\title{
Caries Survey in 3-5 Year Old Children in Dubai Schools
}

\author{
Maitha AlKhayat* \\ Department of Pediatric Dentistrty, European University College, UAE
}

Received: January 03, 2018; Published: January 19, 2018

*Corresponding author: Maitha AlKhayat, Department of Pediatric Dentistrty, European University College, UAE

\section{Abstract}

Introduction: Dental caries is considered the most prevalent chronic disease in the world, which affect individual from all ages. Host acceptability, cryogenic bacteria, fermentable carbohydrates and time are the four elements that are essential for the caries to start. $\mathrm{dmft}$ index is a measurement used to determine the degree of caries in any given population, in which it could help in setting aims and strategies to reduce and prevent this disease.

Aim: The aim of this study was to estimate the caries prevalence and the value of the dmft index of 3 to 5 year old children of Dubai private schools and its association with demographic factors as age and gender.

Methods and Materials: The study was a cross-sectional survey, which examined 3 to 5 year old children, for the presence of caries in their primary dentition. The survey was conducted by three calibrated dentist, who examined the children in the participating schools, in a school class setting using natural light and dental mirrors. Caries were recorded for each primary tooth, following WHO $1987 \mathrm{criteria.} \mathrm{dmft}$ and Significant Caries (SiC) Indices were calculated by age, gender and country of origin. Statistical analysis of the data obtained using parametric tests (t-test and ANOVA), to determine the presence of statistical significant differences.

Results: Two thousand nine hundred fifty-seven children were included in the study. 1527 males and 1430 females, in the male group 134 children were in the 3 year age group, while 630 and 763 children were in the four and five year old age group. The females group consisted of 139 children at 3 year of age, 575 in the four year age group and lastly 716 in the 5 year old age group. Caries prevalence was found to be $25.6 \%$, $36.8 \%$ and $42.2 \%$ for the three age groups respectively. Dmft value was found to be $0.90,1.50$ and 1.72 for the 3,4 and 5 year old age groups, with a dmft value of 1.55 for the total surveyed sample.

Conclusion: Caries prevalence in three, four and five year old children was $25.6 \%, 36.8 \%$ and $42.2 \%$, respectively. Mean dmft score was 1.55 for the total sample, with a breakdown for each group to be: three year old group 0.90 , four year old group 1.50 and five year old group 1.72. The $\mathrm{SiC}$ was found to be 2.07, 4.45 and 5.06; for the three age groups while the $\mathrm{SiC}$ of the total sample found to be 4.55 . Comparison between the age groups showed that the caries prevalence and the SiC index increased as the age increased. The last national survey in 2001 had higher dmft for the 5 year old children in the state of Dubai

\section{Introduction}

Dental caries is the most prevalent chronic disease globally with multi-factorial etiology and pathogenesis WHO.int. Petersen $[1,2]$.

It affects more than 5 billion people of total global population [3]. Children and adults could suffer dental caries at any time; once the oral hygiene measures are compromised, and the contributing factors are met together in specific condition and over a period of time $[4,5]$. Calling dental caries as a multifactorial, makes us think about the elements responsible for such a disease formation. Tooth surface as a host, cryogenic bacteria, fermentable carbohydrates and time are the necessary elements. When they meet in the appropriate proportions formation of the disease will start. Characteristics of the tooth as a host such as, size, structure, anatomy and position of the tooth have an important impact in the progression of the caries and the rate of it. This could explain why the primary teeth are more susceptible to dental caries, having a wider proximal contact surface instead of contact point in permanent teeth $[6,7,8,9,10]$.

Progression of the dental caries is faster which is sent back to the dental tubules arrangement, which is found as S-shaped course in permanent teeth and straight course in the primary teeth [11]. If dental caries are left untreated, then the general health of the individual is at risk. As a multifactorial disease, elimination of the cause will aid in the prevention of the disease. Alteration of a causative factor can be another way to prevent the disease. Dental caries is suggested to have big impacts on the person's life, as it could impair the social function, self-esteem and psychological status Caries prevalence is another measurement, which represents the percentage of the affected population by dental caries at any given time [12]. One of the most important goals regarding global oral 
health was set by the World Health Organization (WHO) in 1979 is to reduce caries prevalence worldwide [2]. Repeated campaigns are designed to fulfil this goal. Most of these campaigns mainly focused on permanent teeth and few were exclusively targeted to the primary dentition using the dmft tool. Prevalence of dental caries among children from 0-5 year had been reported, as part of the WHO goal. Many studies have been conducted in UAE, the Gulf countries and the rest of the World to calculate the prevalence of the dental caries in primary dentition $[13,14,15]$.

The caries prevalence's for 5 years old children worldwide varied from $19.9 \%$ to $94 \%$, while $\mathrm{dmft}$ score for the same age group varied from $0.87(1.16)$ to $9.8(5.5)$. In regard to the children aged 3 and 4 years old, little studies was conducted; which has results for the caries prevalence in 3 year old children between $19.4 \%$ and $85 \%$ and for the 4 year old it was between $23.8 \%$ and $90 \%$. On the other hand the dmft scores worldwide was found to be $0.41(1.16)$ and $0.72(1.62)$ as lowest findings and 7.4(5.5) and 8.8 (5.6) as highest finding for the two age groups respectively $[16,17,18,19,20,21]$.

\section{Aim and Objectives}

The aim of this study was to estimate the caries prevalence and the value of the dmft index of 3 to 5 year old children of Dubai private schools and the association of them with demographic factors as age and gender. The objectives were to compare the caries experience between the 3 age groups, to compare the caries experience between genders and to investigate possible association of the caries prevalence and demographic factors such as age and gender.

\section{Methods and Materials}

This study was part of European University College Oral Health Campaign in Dubai - United Arab Emirates. All the licenses needed for conducting this campaign were obtained from the Ministry of Higher Education and the Ethics committee of European University College that approved the project. Permission for participation in the study was granted from the public and private schools. Written explanation of the aim of the study and request for consent forms were given to the parents, in Arabic and English about the study. Sample From the list provided by the European University College Oral Health Campaign, three schools enrolled preschool and kindergartens children were included in this study. Data were collected during the academic year 2012-2013. Recruitment was based on the age and the positive parental written informed

Table 1.

$\mathrm{N}$

\begin{tabular}{|c|c|c|c|c|c|}
\hline \multirow{2}{*}{ N } & \multicolumn{2}{|c|}{ Caries free } & \multicolumn{2}{c|}{ dmft } & \multicolumn{2}{|c|}{ d } \\
\hline & & & Mean & SD & Mean \\
\hline 3 & 273 & 203 & $0.90^{*}$ & 2.18 & $0.84^{*}$ \\
\hline 4 & 1205 & 761 & $1.50^{*}$ & 2.73 & 1.28 \\
\hline 5 & 1479 & 855 & $1.72^{*}$ & 2.85 & 1.41 \\
\hline Total & 2957 & 1819 & 1.55 & 2.75 & 1.30 \\
\hline
\end{tabular}

* Indicates statistical significant difference. consent. The age of children recruited was between 3 and 5 year old, starting at the day of their 3rd birthday up to the day before their 6th birthday date. The date of birth was obtained from the school files and entered into the computer program.

\section{Procedure}

Children of the chosen age groups were screened for dmft according to WHO 1987 criteria, for caries detection [1]. Examination was performed by three licensed dentist, who were calibrated based on the WHO 1987 criteria, for intra and inter liability score of $\mathrm{k}$ was 0.80 and 0.78 respectively, based on images of sound and carious teeth.

All children were examined at their school classroom under room lighting conditions. Gloves and sterile protocols were used, as well as tongue depressor, which aided in retraction of the tongue, lips and cheeks for better visibility of the teeth. Examination was done by dental mirror only, no dental probes were used. For moisture control and removal of plaque, cotton rolls and gauze were used. According to the WHO 1987 criteria, diagnosis of all primary teeth is based on the presence or absence of the caries. dmft was recorded for decayed, missing (due to caries) and filled teeth. The data from every child were recorded in individual charts. Each chart had an illustration of full primary dentition. The examiners were marking each tooth as decay (dt), missing (mt) or filled (ft). Mean dmft was calculated for the entire sample, as well as individually for each age and gender group separately. Standard deviation (SD) for the dmft was also calculated. Significant caries index ( $\mathrm{SiC}$ ) which represents the mean dmft of the one third of the sample with the highest caries score was also calculated for the total sample as well as for each age group and gender. SiC index gives an indication of the severity of the caries of the most affected part of the population and also illustrates in combination with $\mathrm{dmft}$ the distribution pattern of caries in this population [22].

\section{Statistical Analysis}

Data were statistically analyzed and compared between each age group as well as within each age group by gender. In order to statistically analyze the data of this study, t-test, ANOVA (Analysis of variance) and LSD (least square difference) tests were used at a level of significance $p<0.05$. ANOVA and t-test were used to identify differences between the means of $\mathrm{dmft}$, $\mathrm{dmft}$ components and $\mathrm{SiC}$ index from different groups. When ANOVA detected a difference between groups then LSD was used to detect which groups were different. 


\section{Results}

The sample consisted of two thousands nine hundreds fiftyseven child (Table 1). 1527 males (51.6\%) and 1430 females (48.4\%), 273 (9.2\%) in the 3 year old group and 1205 (40.8\%) and $1479(50.0 \%)$ in the 4 and 5 year old group, respectively. 3 year old children group consisted of 273 children, 134 (49.1\%) males and 139 (50.9\%) females, there were $203(74.4 \%)$ caries free children. Of the male sample 104 children $(77.6 \%)$ were caries free while of the females 99 children $(71.2 \%)$ were free of caries for the 3 year old sample. Mean dmft (SD) was 0.90 (2.18) and dt $=0.83$ (2.09), $\mathrm{mt}=0.02(0.27)$ and $\mathrm{ft}=0.03$ (0.19). Comparing the caries experience between males and females the result showed that males have lower dmft values, with a mean $\mathrm{dmft}$ (SD) of 0.69 (1.71), while for the females the mean dmft (SD) was 1.09 (2.53). Similarly, all of the dmft components in the male group presented lower values as compared to females; dt 0.67 (1.69), mt 0.02 (0.27) and $\mathrm{ft} 0.02$ (0.14) for the males and dt 1.00 (2.41), mt $0.02(0.27)$ and $\mathrm{ft}$ $0.04(0.23)$ for the females. Differences in the means between the two genders were explored with ANOVA which did not show any statistically significant difference between the means of $\mathrm{dmft}(\mathrm{F}=$ 1.52), $\mathrm{dt}(\mathrm{F}=1.30), \mathrm{mt}(\mathrm{F}=1.51)$ and $\mathrm{ft}(\mathrm{F}=0.86)$. Moreover there were more males without caries $(77.6 \%)$ compared to females (71.2\%).

$\mathrm{SiC}$ value for the males was 2.07 (2.45) which are lower than the females 3.23 (3.50). 4 year old children group this age group included 2015 children, 630 (52.3\%) were males and 575 (47.7\%) females. There were 761 (63.2\%) caries free children, 382 (60.6\%) of the males and $379(65.9 \%)$ of the females. The $\mathrm{dmft}$ values were found to be 1.50 (2.73) for the total sample, with $d t=1.28(2.48)$, $\mathrm{mt}=0.02(0.23)$ and $\mathrm{ft}=0.20(0.72)$. It was also observed that $\mathrm{dmft}$ value for the males was 1.54 (2.69), with $\mathrm{dt}=1.33$ (2.69), $\mathrm{mt}=0.03$ $(0.30)$ and $\mathrm{ft}=0.19(0.71)$, while for the females the respective values were, $\mathrm{dmft}=1.45(2.77), \mathrm{dt}=1.45(2.77), \mathrm{mt}=0.01(0.12)$ and $\mathrm{ft}=0.21(0.74)$. The mean $\mathrm{dmft}$ and $\mathrm{dt}$ was higher in the male group than the female group while females had higher $\mathrm{dt}$ and $\mathrm{ft}$ values. SiC value for the 4 year old sample was found to be 4.40 (3.11), while the $\mathrm{SiC}$ values for males and females were 4.44 (2.99) and 4.33 (3.25), respectively 5 year old children group The 5 year old group consisted of 1479 children, 763 (51.5\%) males and $716(48.5 \%)$ females. The mean $\mathrm{dmft}$ value of the total sample was 1.72 (2.99), with $\mathrm{dt}=1.41$ (2.55), $\mathrm{mt}=0.03(0.26)$ and $\mathrm{ft}=$ 0.29 (0.95). Comparing males to females in the caries experience within this group showed that the males had higher dmft value 1.85 (2.99) while the females had 1.59 (2.69). In regard to the dmft component, $\mathrm{dt}$, $\mathrm{mt}$ and $\mathrm{ft}$ values; it was 1.53 (2.73), 0.04 (0.23) and $0.28(0.87)$ for the males, and 1.28 (2.34), $0.04(0.29)$ and 0.31 (1.04) for the females, respectively. Significant Caries index $\mathrm{SiC}$ for the total sample in this age group was 4.86 (2.97). Males presented statistically significant higher $\mathrm{SiC} 5.02$ (3.05) than females 4.51 (2.82) using Student's t-test $(t=5.11)$.

Comparing between the three age groups (3, 4 and 5 year old) The sample consisted of 1138 (38.5\%) children with caries and 1819 (61.5\%) caries free children. Caries prevalence for the 3 year old group was $25.6 \%$ (70 children) and $36.8 \%$ ( 444 children) and
$42.2 \%$ ( 624 children) for the 4 and 5 year old group respectively. The mean dmft value was increasing as the age of the sample was increasing. The lowest $\mathrm{dmft}$ value was observed for the 3 year old group 0.90 (2.18) and then it increased for the 4 year old 1.50 (2.73) and the highest value was observed for the 5 year old children 1.72 (2.85). Regarding the dmft components, dt (decayed teeth) ranged between 0.84 (2.09) and 1.41 (2.55) and dt was the component with the higher contribution to the dmft index while the component with the lowest contribution was the $\mathrm{ft}$ which ranged between $0.03(0.20)$ and $0.29(0.95)$. ANOVA showed that among the three age groups there was statistically significant difference in the mean $\mathrm{dmft}(\mathrm{F}=10.81), \mathrm{dt}(\mathrm{F}=6.16)$ and $\mathrm{ft}(\mathrm{F}=13.14)$ values, while there was no statistical significance difference in $\mathrm{mt}(\mathrm{F}=2.74)$ component. LSD test was used to explore the differences between the means that ANOVA suggested. LSD test showed that there was statistically significant increase of the mean $\mathrm{dmft}$ and $\mathrm{dt}$ values as the age of the children progressed. It was also found that only the three year old mean value of the dt component was different from the means of the other ages which had no significant difference.

Comparing dmft and its component between the three age groups showed that 5 year old children had higher value 0.9 (2.18), as compared with the 3 and 4 year old groups with 1.5 (2.73) and 1.72 (2.85), respectively. About the dmft components, dt was highest among the 5 year old group 1.41 (2.55) followed by the 4 year dmft 1.28 (2.48) and the 3 year old 0.84 (2.09). mt component was also highest among the 5 year old group 0.04 (0.26), the lowest was 4 year old children 0.02 (0.23), 3 year old group scored 0.03 (0.28). The values for $\mathrm{ft}$ was $0.03(0.2)$ for the 3 year old group, 0.2 $(0.72)$ for the 4 year old and $0.29(0.95)$ for the 5 year old group. Dental caries formation in primary dentition increases with age, as the primate spaces and the physiological spaces reduces. Lack of hygiene and interproximal cleaning, aids in the increase of proximal caries as well the flat contact surfaces, which increase the progress of these kinds of caries. ANOVA was also used to test the difference of the $\mathrm{dmft}$ values between the males and females among the different age groups. Statistically significant difference was found between the different mean dmft male values ( $F=10.19)$ and LSD showed that the difference existed between all the three groups. Statistically significant difference was also observed in the $\mathrm{dt}$ and $\mathrm{ft}$ components of the dmft ( $\mathrm{F}=6.71$ and 7.10). LSD showed that males had statistically significant differences in $\mathrm{dt}$ and $\mathrm{ft}$ values among all three age groups. In female groups mean dmft did not have statistically significant difference, the only observation with statistically significant difference was seen in the mean $\mathrm{dmft}$ component, specifically $\mathrm{ft}$ value $(\mathrm{F}=6.17)$. LSD test showed that all the three means in the $\mathrm{ft}$ females component were statistically significant different.

\section{Discussion}

United Arab Emirates has improved in many aspects regarding the dental health and the dental awareness of the population. Never the less through the few last year dental caries are still considered a national health problem among adult and children. Previously conducted National Survey in 2001 by El Nadeef et al. [23] studying dental caries among children, found dmft in 5 year old children 
5.1, and specifically 6.6 for the state of Dubai. In this study 5 year old children dmft score was found to be 1.72 . This is showing a decline of the dmft value as a result which could be attributed to the increase awareness in regard to dental health and the development of the dental care facilities. In this survey it is interesting to note the large drop of the dmft scores compared to previous studies. This big difference was primarily due to a substantial decrease of the $\mathrm{dt}$ components suggesting a drop in caries presence in the population. Despite this drop dt still remains the major contributing factor of the $\mathrm{dmft}$ index suggesting that even today caries are left untreated in children. Probably this reflects an attitude among the parents not identifying caries of primary teeth as a disease which needs treatment. In the past years there have been many awareness programs and educational campaigns conducted in the UAE trying to change this attitude. Towards the same direction this study shows also a slight increase in the $\mathrm{ft}$ component between the two studies. The awareness of the public regarding caries and caries prevention cannot therefore explain the substantial drop of the dmft values. Most likely this drop should be attributed to other confounding factors like wider use of fluoridated toothpaste and fluoridated products or healthier eating habits.

For the three and four year old group no studies were performed in Dubai, thus no data were available previously for the state of Dubai at the time of conducting this study. The results obtained from this study are the first data for this age group in Dubai, although the sample was not representative of the total population, the data may be considered as a pilot sample for an upcoming thorough investigation. AlHosani, Rugg-gunn 1998 conducted a study which included 4 and 5 year old children, in the western part of the UAE, AbuDhabi, AlAin and The West region. Prevalence of caries in the four year old children was ranging between 71-86\% [24] while for the five year old it was between $82-94 \%$. dmft was found to be 8.4 in AbuDhabi, 8.6 in AlAin and 5.7 in The West region. Comparing this result to the result obtained from this study, we can conclude that the dmft value in the state of Dubai is lower than the other UAE regions. Another study by Hashim R 2006 [25] in the city of Ajman found dmft in 5 year old children 4.0 (4.1), with caries prevalence of $72.9 \%$, while in this study the prevalence was found to be $42.2 \%$. Comparing the present findings to those conducted in the Middle East countries, findings suggest that this study is having lower $\mathrm{dmft}$ and caries prevalence than those conducted in the last decade. Paul, 2003 found in KSA caries prevalence of $83.5 \%$ and dmft of 7.1 (6.1) Paul 2003 [26]; Salem, Holm 1985 [27] had mean dmft 1.2 (0.08) for children age 3-5 year old in KSA, Morris et al. 1999 [28] had $19 \%$ dental prevalence in 18-48 months old children in Kuwait, also in Kuwait in 1993, Martomaa H found 22\% prevalence in 3-7 year old children in Kuwait 1993 and Wyne, AH, 2008 found mean dmft 6.1 (3.9) for 3-5 year old children [29].

Among the 3 year old children the lowest dental caries (19.4\%) was experienced in India 2001 [30], while the highest (85\%) was in Philippines 2003 [31]. The result of this study falls in between this range, close to the lower end being $26 \%$. There are no previous surveys conducted in the UAE for this age group in order to compare the result of this study. The only possible comparison can be done with surveys conducted in other countries of the world. We can only have an approximate comparison with other studies of the Gulf region since they report $\mathrm{dmft}$ and prevalence values for a range of ages that include the three year group making a direct comparison impossible. Viewing the previous studies conducted for the 3 year old children worldwide and comparing those findings with the finding of this study, we could conclude that the dmft score of this age group for the city of Dubai is being the lowest compared to other studies conducted in other countries in the world. The highest $\mathrm{dmft}$ value 7.4 (5.5) was reported in the Philippines 2003 [31], followed by 5.5 (4.5) in China 2002 [32]. dmft value in India varied between 0.41 (1.16) in 2001 [61] and 4.43 (2.33) in 2009 [9]. Brazil's dmft values reported in 2009 were the lowest 1.13 (1.90) for 3 year old children [33], while in 2004 it was 2.10 [34].

For four years old children group the highest caries prevalence was found to be between $71 \%$ and 86\% in AbuDhabi 1996 [24] which is very high compared to $37 \%$ in this study. In India (2001) [30], the reported caries prevalence was the lowest 28.2\% [35], followed by Brazil 2007 with 23.8\%. Philippines 2003 had the highest caries prevalence of $90 \%$ for this age group [31].

Comparing to the previous studies from different regions of the world, it could be noticed that dmft of this study falls in the lowest range of all dmft values of this age group. Australia 2002 [36] and Brazil 2009 [33] had the lowest dmft values 1.29 (2.74) and 1.42 (3.11), respectively. Next comes the dmft value of this study 1.50 (2.73).

Most of the dmft studies are conducted for 5 year old children. After the announcement of WHO goal for the year 2000, of having caries prevalence to be less that $50 \%$ for 5 year old children, many studies have been conducted all over the world to have this baseline and efforts have been put together afterwards to achieve the goal in that period. It worth mentioning that these efforts had been successfully noticed as dmft values had been significantly decreasing . In the UAE, significant decrease in the $\mathrm{dmft}$ value could be noticed between 1996 and 2001, and even further decrease could be noticed in dmft value of this study. Even though this decrease is obvious, the WHO target of having dmft score below 3 for the 5 year old children, haven't been achieved yet. KSA 2000 [37], have achieved WHO target by having 0.95 (2.03) in a specific population. Other countries like India 2001 [30], Australia 2002 [33], India 2006 [38], Brazil 2007 [35], China 2008 [39], Brazil 2009 [29], Italy 2009 [40], Norway 2010 [41] and Greece 2011 [42] had also reach the target goal but after the set date. Highest dmft value could be observed for Philippines 5 year old children 2003 [26], followed by KSA 2008 [29] and FYROM 2014 [43] with same dmft value of 6.1. In regard to the caries prevalence in the 5 year old children, the highest prevalence could be observed in the Philippines 2003 [31] (94\%) and in UAE 1996 [24] (94\%).

The lowest prevalence was reported by Ferreira et al., Italy 2007 [35] (19.9\%). It worth mentioning here that India 2001 [30], Kuwait 2002 [44], Brazil 2004+2007+2009 [34,35,33], UK 2006 [45], Italy 2009 [40], Norway 2010 [41] and Greece 2011 [16] all had caries prevalence that falls below 50\%, which 
is the goal set by WHO in 2000 Khan 2014 [46] had reported a systemic review of the dmft in the Arab world for children aged between 3 and 10 year of age, for the period from 2000 to 2012 . In this report Kingdom of Saudi Arabia in 2000 [37] reported the lowest dmft values 0.95 while in 2007 [16], dmft value was the highest 7.1. These studies were conducted in different places in KSA, follow up studies worth to be conducted in the same places to have a frank comparison between the new and old obtained $\mathrm{dmft}$ values. According to the finding results in this study, and due to the selection of the sample, which was drawn mainly from private schools and the fact that those children are from a medium socioeconomic status families, the result are not representative to the children population in the city of Dubai. Furthermore, the three examiners were calibrated through photographs, which may have contributed to some bias for caries underestimation. Also the caries were scored according the 1987 WHO caries criteria which does not account for caries with underlining dark shadow from dentin, lesions that are usually accounted in WHO 1997 criteria, used by most of the epidemiological studies $[47,48,49,50,51,52,53,54,55$, $56,57,58,59]$. Since the introduction of $\mathrm{dmft}$ and $\mathrm{SiC}$ indices 1938 [60], it was considered as ideal indices, as they met a number of criteria, which made them useful epidemiological indicators. These criteria included simplicity, reliability versatility and statistical manageability $[61,62,63,64,65,66,67,68]$. dmf describes the mean experience of dental caries in specific population, without giving any information about the level of the dental caries in the most affected population. On the other hand significant caries index (SiC), does represent the mean $\mathrm{dmft}$ in the highest one third of the population with the highest dmft scores giving a picture of the severity of the disease in the most affected portion of the sample.

The SiC index indicated that the study sample had a score of 2.07 (2.45) for the 3 year old group, 4.45 (2.99) for the 4 year old group and 5.06 (3.13) for the 5 year old group. The SiC score for the 5 year old children is considered of lower score compared to the $\mathrm{SiC}$ indices from other part of the world, for example in $\mathrm{SiC}$ score of 5 year old children in Greece 2011 was 5.01 [69], while In Sri Lanka 20125.84 for 4 and 5 year old children [70]. In the Republic of FYROM, SiC index was found to be 8.83 [43] found $\mathrm{SiC}$ in Turkish children to be of 7.75 [71] and according to in Italy, $\mathrm{SiC}$ for 5 year children was 5.32 [40]. Recommendations since the National survey of dental caries in United Arab Emirates is almost fifteen year old, efforts have to be put together in a governmental and personal level to update this important data, which will aid in thorough prevention of the problem. Health education of the parents and the children has to start as early as possible, which will aid in prevention and detection of the problem at its initial stages. Dental visits have to be scheduled annually for routine checkups. Parent's education regarding the importance of the primary teeth to the child's overall health has to be emphasized; this important information will result in maintaining healthy children .

\section{Conclusion}

Caries prevalence in three, four and five year old children were found to be $25.6 \%, 36.8 \%$ and $42.2 \%$, respectively. Mean $\mathrm{dmft}$ score for the total sample was 1.55 (2.75), with a breakdown for each group to be: three year group 0.90 (2.18), four year group 1.50 (2.73) and five year old group 1.72 (2.85). The $\mathrm{SiC}$ was found to be 2.07 (2.45), 4.45 (2.99) and 5.06 (3.13); for the three age groups, 3,4 and 5 year old children, respectively [61-68]. The SiC for the total sample was found to be 4.55 (3.12). Comparison between the age groups showed that the caries prevalence and the $\mathrm{SiC}$ index increased as the age increased. The last national survey in 2001 had higher dmft for the 5 year old children in the city of Dubai. The prevalence of primary dental caries is greater in 5 year old children, especially in male children. Dental caries formation in primary dentition increases with age, as the teeth are exposed to the cariogenic bacteria for longer time. The sample consists of only private schools in Dubai; dmft scores are lower than the previous national survey which was conducted at public schools. Dental awareness is still minimum among the population new national survey has to be conducted to update the previous data [69-73].

\section{References}

1. WHO (1987) Oral health surveys basic methods $3^{\text {rd }}$ edn, WHO Geneva. World Health Organization. In Wigen TI, Wang NJ (2010) Caries and background factors in Norwegian and immigrant 5 year old children. Community Dentistry and Oral Epidemiology 38(1): 19-28.

2. Petersen PE, Bourgeois D, Ogawa H, Estupinan Day S, Ndiaye C (2005) The global burden of oral diseases and risks to oral health. Bulletin of the World Health Organization 83(5): 661-669.

3. Al Mutawa S, Shyama M, Al Duwairi Y, Soparkar P (2006) Dental caries experience of Kuwaiti schoolchildren. Community Dental Health 23(1): 31-36.

4. Azizi Z (2014) The Prevalence of Dental Caries in Primary Dentition in 4 to 5 Year Old Preschool Children in Northern Palestine. International Journal of Dentistry 1-5.

5. Bhatia HP, Srivastava B, Khatri, Aggarwal A (2012) Prevalence of Dental Caries Among 3-15 Year Old School Children in Ghaziabad City and its Adjoining Areas A Correlated Survey. Journal of Oral Health and Community Dentistry 135-140.

6. Cariño K, Shinada K, Kawaguchi Y (2003) Early childhood caries in northern Philippines. Community Dent Oral Epidemio 31(2): 81-89.

7. Chowdhary NL, Subba Reddy V (2010) Dentine comparison in primary and permanent molars under transmitted and polarised light microscopy: An in vitro study. Indian Soc Pedod Prev Dent 28(3): 167172.

8. Dawani N, Nisar N, Khan, Syed S, Tanweer N (2012) Prevalence and factors related to dental caries among pre-school children of Saddar town, Karachi, Pakistan : a cross-sectional study. BMC Oral Health 12-59.

9. Masumo R, Bardsen A, Mashoto K, Åstrøm AN (2012) Prevalence and socio behavioral influence of early childhood caries, ECC, and feeding habits among 6-36 months old children in Uganda and Tanzania. BMC Oral Health 12(1): 24.

10. Wyne AH, Khan NB (1988) Caries prevalence in 2 and 3 year old children of adelaide australia. Odonto-Stomatologie Tropicale 21(88): 22-23.

11. Wyne AH (2008) Caries Prevalence Severity and Pattern in Preschool Children. Journal of Contemporary Dental Practice 9(3): 1-8.

12. Limbu S, Dikshit P, Mehata S, Thapa P (2013) Dental Caries prevalence and treatment needs in children aged upto16 years attending at Kantipur Dental College and Hospital. Journal of Nepal Dental Association 13(2): 9-15. 
13. Wyne AH, Al Ghorabi BM, Al Asiri YA, Khan NB (2002) Caries prevalence in Saudi primary schoolchildren of Riyadh and their teachers oral health knowledge attitude and practices. Saudi Med J 23(1): 77-81.

14. Kiwanuka SN, Trovik TA (2004) Dental caries experience and its relationship to social and behavioural factors among 3-5 year old children in Uganda 336-346.

15. Moynihan P, Petersel PE (2007) Diet nutrition and the prevention of dental diseases. Public Health Nutrition 7(1): 201-226.

16. Ferro R, Besostri A, Olivieri A (2009) Caries prevalence and tooth surface distribution in a group of 5-year-old Italian children. European Archives of Paediatric Dentistry 10(15): 33-38.

17. Tewari S (2001) Caries experience in 37 year old children in Haryana. Journal Indian Soc Prev Dent 19(2): 52-56.

18. Tinanoff N, Kanellis MJ, Vargas CM (2002) Current understanding of the epidemiology, mechanisms and prevention of dental caries in preschool children. Pediatric Dentistry 24(6): 543-551.

19. Hazza AA, Rawashdeh M, Al Nimri K, Al Habashneh R (2011) Dental and oral hygiene status in Jordanian children with cleft lip and palate a comparison between unilateral and bilateral clefts. International J Dent Hyg 9(1): 30-36.

20. Tsai A, Chen C, Li L, Hsiang C, Hsu K (2006) Risk indicators for early childhood caries in Taiwan, (11): 437- 445.

21. Mahejabeen R, Sudha P, Kulkarni SS, Anegundi R (2006) Dental caries prevalence among preschool children of Hubli: Dharwad city. J Indian Soc Pedod Prev Dent (24) :19-22.

22. Tsai AI, Chen CY, Li LA, La HC, Hsu KH (2006) Risk indicators for early childhood caries in Taiwan. Community Dent Oral Epidemiol 34(6): 437 445.

23. Tyagi P (2009) The Prevalence and Pattern of Dental Caries in PreSchool Children. People's Journal of Scientific Research 2: 1-4.

24. Brathall D (2000) Introducing the Significant Caries Index together with a proposal for a new global oral health goal for 12 year olds. Int Dent J 50(6): 378-384.

25. Nainar SMH, Wyne AH (1998) caries pattern of high caries preschoo children attending a dental clinic in riyadh Saudi Arabia. The Saudi Dental Journal 10(2): 80-85.

26. Dowd FJ (1999) Saliva and dental caries. Dent Clin North Am 43(4): 579 597.

27. Perera PJ, Abeyweera NT, Fernando MP, Warnakulasuriya TD, Ranathunga N (2012) Prevalence of dental caries among a cohort of preschool children living in Gampaha district, Sri Lanka a descriptive cross sectional study. BMC Oral Health 12(1): 49.

28. El Nadeef M, Hassab M, Al Hosani E (2010) National survey of the oral health of 5 year old children in the United Arab Emirates. Eastern Mediterranean Health Journal 16(1): 51-56.

29. Farsi A (2010) Dental visit patterns and periodontal treatment needs among Saudi students. Eastern Mediterranean Health Journal 16(7): 801-806.

30. Narang R, Saha S, Kumari M, Mohd S, Saha S (2013) The Maternal Socioeconomic Status and the Caries Experience Among 2-6 Years Old Preschool Children of Lucknow City India. Journal of Clinical and Diagnostic Research 7(7): 1511-1513.

31. AlHosani E, Rugg gunn A (1998) Combination of low parental educational attainment and high parental income related to high caries experience in pre-school children in Abu Dhabi. Community Dent Oral Epidemiol (26): 31-36.

32. Oulis CJ, Berdouses ED, Mamai homata E, Polychronopoulou A (2011) Prevalence of sealants in relation to dental caries on the permanent molars of 12 and 15-year-old Greek adolescents . A national pathfinder survey. BMC Public Health 11(1): 100.
33. Agarwal DSS, Reddy CVK, Machale P (2012) Early Childhood Caries Prevalence Severity and Pattern in 3-6 Year Old Preschool Children of Mysore City, Karnataka. Pesquisa Brasileira Em Odontopediatria E Clínica Integrada 12(4): 561-565.

34. Grubbel AA (1944) A measurement of dental caries prevalence and treatment service for decidous teeth. J Dent Res (23): 163-168.

35. Sofowora CA, Nasir WO, Taiwo M, Adesina OA (2006) Caries experience in the primary Dentition of Nursery School. African Journal of Oral Health 2(1):19-25.

36. Hallett KB, Rourke PKO (2002) Dental caries experience of preschool children from the north Brisbane region Australian Dental Journal 47(4): 331-338.

37. Ueda E, Dezan C, Frossard W, Salomão F, Morit M(2004) Prevalence of dental caries in 3 and 5 - year old children living in a small brazilian city. J Appl Oral Sci 12(1): 34-38.

38. Du M Luo, Y, Zeng X, Alkhatib N, Bedi R (2007) Caries in preschool children and its risk factors in provinces in China. Quintessence International 38(2): 143-152.

39. Y Li (2002) Predicting Caries in Permanent Teeth from Caries in Primary Teeth An Eight year Cohort Study. J Dent Res 81(8): 561-567.

40. GB Al, Amri MY, Stewart BL (2005) Status of dental caries among 4-9 year-old children attending dental clinic in a military hospital in Tabuk KSA. Saudi Dental Journal 17(3): 126-131.

41. Paul TR (2003) Dental health status and caries pattern of preschool children in Al Kharj Saudi Arabia. Saudi Med J 966(April): 22-24.

42. Khan SQ (2012) Dental caries in Arab League countries a systematic review and meta analysis. 1-8.

43. Vadiakas G, Oulis CJ, Tsinidou K, Polychronopoulou A (2012) Oral hygiene and periodontal status of 12 and 15 year old Greek adolescents a national pathfinder survey. European Archives of Paediatric Dentistry 13(1): $11-20$.

44. Bagramian RA (2009)The global increase in dental caries. A pending public health crisis. Dent (22): 3-8.

45. Petersen PE (2003) The World Oral Health Report 2003 WHO Global Oral Health Programme. Community Dentistry and Oral Epidemiology 31(1): 3-23.

46. Namal N, Yüceokur AA, Can G (2009) Significant caries index values and related factors in 5-6 year old children in Istanbul Turkey. Eastern Mediterranean Health Journal 15(1): 178-184.

47. Vargas C M, Monajemy N, Khurana P, Tinanoff N (2002) Oral health status of preschool children attending Head Start in Maryland 2000. Pediatric Dentistry 24(3) 257-263.

48. Wigen TI, Wang NJ (2010) Caries and background factors in Norwegian and immigrant 5-year-old children. Community Dent Oral Epidemiol 38(1): 19-28.

49. Phipps KR, Ricks TL, Manz MC, Blahut P (2012) Prevalence and severity of dental caries among American Indian and Alaska Native preschool children. Journal of Public Health Dentistry 72(3): 208-15.

50. Wyne A, Darwish S, Adenubi J, Battata S, Khan N (2001) The prevalence and pattern of nursing caries in Saudi preschool children. Int J Paediatr Dent 11(6): 460.

51. Ferro R, Besostri A, Olivieri A (2009) Caries prevalence and tooth surface distribution in a group of 5-year-old Italian children. European Archives of Paediatric Dentistry 10(15): 33-38.

52. Ambarkova V, Apostolova D (2014) Dental Caries Experience among 5 Year Age Children from Two Municipalities Berovo and Pechčevo in the Eastern Region of the Republic of Macedonia. Journal of Dental Applications 1(4): 61-67.

53. Al Banyan RA, Echeverri EA, Narendran S, Keene HJ (2000) Oral health 
survey of 5-12 year old children of National Guard employees in Riyadh Saudi Arabia. Int J Paediatr Dent 10(1): 39-45.

54. Marya (2011) A Textbook of Public Health Dentistry (p. 547).

55. Pitts NB, Chestnutt IG, EvansD, WhiteD, Chadwick B, et al. (2006) The dentinal caries experience of children in the United Kingdom 2003. British Dental Journal 200(6): 313-20.

56. Al Khadra TA (2011) prevalence of dental caries and oral hygiene status among down's syndrome patients in riyadh. Pakistan Oral Dental Journal 31(1): 115-117.

57. Qadri G, Nourallah A, Splieth CH (2012) Early childhood caries and feeding practices in kindergarten children. Quintessence International 43(6): 503-510.

58. Al Malik M, Holt R, Bedi R (2003) Prevalence and patterns of caries rampant caries and oral health in two to five year old children in Saudi Arabia. J Dent Child 70(3): 235-342.

59. Rodd HD, Davidson LE, Bateman PM, Lunn HD (2002) Caries experience and dental attendance of Somali children living in a British city. Eur J Paediatr Dent 3(4):210-216.

60. Dini E, Holt R, Bedi R (2000) caires 3-4y Brazil Community. Dent Oral Epidemiol( 28): 241-248.

61. Hashim R, Thomson W, Ayers KMS, Lewsey JD, Awad M (2006) Dental caries experience and use of dental services among preschool children in Ajman UAE. International Journal of Paediatric Dentistry (16): $257-$ 262.

62. Salem GMA, Holm S (1985) Dental caries in preschool children in Gizan, Saudi Arabia. Community Dent Oral Epidemiol 13-176.

63. Morris RE, Gillespie G, Dasht A, Gopalakrishnal NS, Al Za abi F (1999) Caries in Kuwait. Eastern Mediterranean Health Journal 5(5): 10141022.

64. Khan SQ (2014) Dental caries in Arab League countries: a systematic review and meta analysis. International Dental Journal 64(4): 173-180.
65. Ferreira SH, Béria JU, Kramer PF, Feldens EG, Feldens CA (2007) Dental caries in 0 to 5 year old Brazilian children prevalence severity and associated factors 289-297.

66. Li KZ, Li, X, Hu D Y, Fan X, Nie L (2008) Prevalence of deciduous tooth caries in 780 children aged 5 years. Hua Xi Kou Qiang Yi Xue Za Zhi 26(1): 70-72.

67. Sayegh A, Dini E, Holt RD, Bedi R (2002) Caries in preschool children in Amman Jordan and the

relationship to socio demographic factors. Int Dent J 52(2): 87-93.

68. Shyama M, Al Mutawa SA, Morris R E, Sugathan T, Honkala E (2001) Dental caries experience of

disabled children and young adults in Kuwait. Community Dental Health 18(3): 181-186.

69. Carvalho FS, Carval CAP, Basto R da S, Xavier A, Merlini S P, et al. (2009) Dental caries experience in preschool 8(2): 9-12.

70. Al Malik M, Holt RD (2000) The prevalence of caries and of tooth tissue loss in a group of children living in a social welfare institute in Jeddah Saudi Arabia. Int Dent J 50(5): 289-292.

71. Al mutawa S, Al duwairi Y, Honkala E, Honkala S, Shyama M (2002) Oral Health The Trends of Dental Caries Experience of Children in Kuwait. Dental News IX (III): 9-13.

72. Oulis CJ, Tsinidou K, Vadiakas G, Polychronopoulou A, Athanasouli T (2011) Caries prevalence of 5-12 and 15 year old Greek children A national pathfinder survey. Community Dental Health XX 1-8.

73. Ferro R, Besostri A, Olivieri A (2009) Caries prevalence and tooth surface distribution in a group of 5-year-old Italian children. European Archives of Paediatric Dentistry 10(15): 33-38.

74. Kruger E, Dyson K, Tennant M (2005) Pre school child oral health in rural Western Australia. Australian Dental Journal 50(4): 258-262.

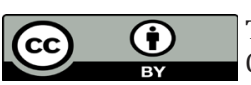

This work is licensed under Creative Commons Attribution 4.0 License

DOI: $10.32474 /$ IPDOAJ.2018.01.000101

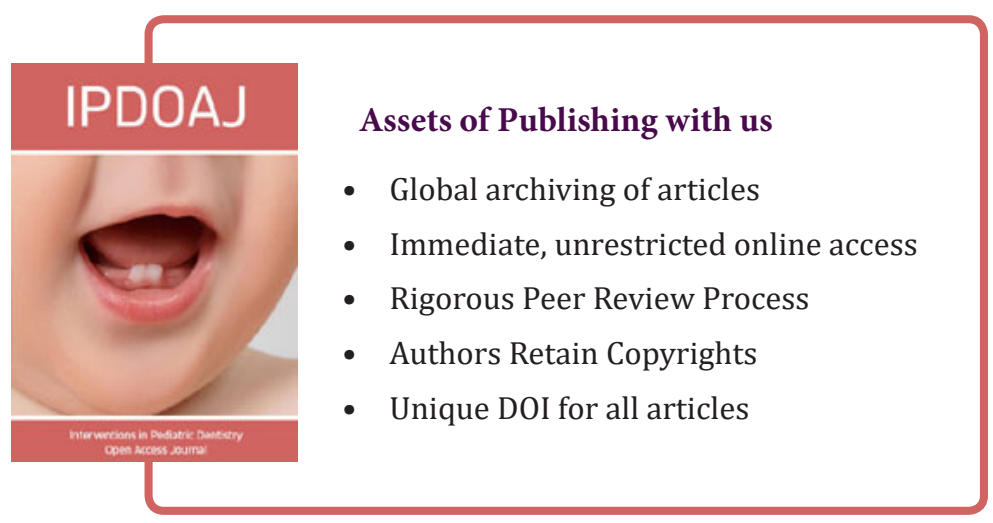

